\title{
A Comparative Study between External Fixation Versus Locking Compression Plate in Managemento Extra Articular Proximal 1/3 Tibia Fractures
}

\author{
Ismail Jan ${ }^{1 *}$, Xiaotao Li ${ }^{1}$, Shahid Alam², Andleeb Manzoor ${ }^{3}$ \\ ${ }_{1,1 *}$ Department of Orthopedic Surgery -III. The First Affiliated Hospital of Jiamusi University \\ Jiamusi city, Heilongjiang province, P. R China \\ drismailjan@gmail.com \\ ${ }^{2}$ Department of Vascular Surgery \\ imoonsk@hotmail.com \\ ${ }^{3}$ School of Medicine Jiamusi University \\ smartyandleeb@gmail.com
}

\begin{abstract}
:
Background

Fractures occurring in the proximal tibia of extra articular type often results from high-energy trauma with comminution and displacement problems. Most authorities agree that operative management of these fractures is best option in order to optimize patient outcomes. We want to assess which treatment method would be a best option for the patient with less complications and quicker recovery.
\end{abstract}

Objective

To evaluate the effects of external fixation and LCP techniques in the management of extra-articular proximal third tibial fractures in terms of bone union time, infection, postoperative complications, operative time, bleeding and cost effectiveness of both techniques.

\section{Materials and Methods}

The study was carried out on 40 patients with proximal third tibia fractures of AO classification type 41 A2 (transverse metaphyseal) and 41 A3 (comminuted metaphyseal) who received surgical treatment at the orthopedic units of the first affiliated hospital of Jiamusi university, between December-2014 to March-2016. The subjects of the study were patients aging between 35 45 years old, 22 male and 18 female.Patients were divided into 2 groups depending on the surgical treatment received; observation group comprised of 20 patients treated by external fixation and the control group comprised of 20 patients treated by Open reduction internal fixation with locking compression plate. Pathological fractures, fractures due to malignancy were excluded from the study. Clinical and radiological follow-up was performed at one month, 2 months, 3 months, 6months and 12 months post operatively for both groups. Patients were systematically assessed for knee function, post operative infections, healing time, intra operative bleeding and surgical time, state of reduction after one week. Knee function was graded using Rasmussen Knee score. Clinical data was summarized and a data base established after which SPSS18.0 software was used to choose the appropriate statistical analysis method and conclusions were obtained.

\section{Results}

32 patients showed up for post operation checkup after one-month, 2-months,3-months,6-months, after 1 year 20 patients showed up. At one week post op, radiological assessment showed that 18-patients (93\%) got anatomical reduction in LCP group as compared to 16-patients (80\%) in the external fixation group. Average duration of bone union in external fixation was 14-weeks and that in LCP group 16-weeks. 2 cases in the external fixation group had pin tract infection, which were resolved with administration of antibiotics and local pin site care; no infection was noted in the LCP group. There were 2 cases of delayed union in LCP group and these were re operated using locking plates and auto bone grafts. No deep venous thrombosis, pneumonia or bed sores developed in any group patients. There was one case of bed sore in LCP group. There was initial knee stiffness in EF group and mean knee range of motion was 122 degree and that in LCP group as 126 degree. Continuous passive motion was started as soon as the pain subsided. After 2-months and 6-months follow ups, no radiographic signs of osteoarthritis detected. Mean Rasmussen knee score was good 25 in EF group patients and good 24.5 in LCP group. Mean weight bearing time was 13-weeks post operatively for both groups. No cases of compartment syndrome detected in both groups. Checkup after 1-year of both group patients, all were full weight bearing with satisfactory range of motion. 


\section{Conclusions}

Both methods of treatment have good results. Treatment with External fixation is less invasive, less soft tissue dissection and less infection chances are there. Also short operative time, less time to bone healing, less bleeding and no need for surgical removal of implant, less post operative complications related to anesthesia and comparatively cost effective method.

Keywords: external fixation, proximal tibia, fractures, locking compression plate.

$\begin{array}{ll}\text { Abbreviations: } & \\ \text { EF } & \text { External fixation } \\ \text { ORIF } & \text { Open reduction internal fixation } \\ \text { LCP } & \text { Locking Compression Plate } \\ \text { BO } & \text { Biological Osteosynthesis } \\ \text { AO } & \text { Arbeitsgemeinschaft für Osteosynthesefragen } \\ \text { MIPPO } & \text { Minimally Invasive Percutanous Plate Osteosynthesis } \\ \text { MIPO } & \text { Minimally Invasive Plate Osteosynthesis } \\ \text { DVT } & \text { Deep Venous Thrombosis } \\ \text { Ext. Fix } & \text { External fixation }\end{array}$

\section{INTRODUCTION}

Extra-articular proximal tibia fracture is not uncommon and accounts for about 5-11\% of all tibial fractures ${ }^{[1,2,3,4]}$. Many problems related to treatment and accompanying injuries complications arose and treatment of such fractures made surgeons to develop several fixation techniques and approaches with meager attention to the optimal management plan. Conventional (AO) plating requires exposure of the fracture and extensive dissection of the soft-tissue, thus carrying the risks of bleeding, infection and soft-tissue healing problem. Although problems like soft-tissue healing and avoiding deep infections can be largely sorted out with external fixator, yet it bears the risks of malunion, nonunion and pin track infection; another big limit to this procedure is patient's dissatisfaction .Introduction of the locking plate (LCP) in the fracture fixation, the fixation of proximal tibia fracture has brought a dramatic change. Fixation of proximal third tibia fractures with the locking plates has demonstrate excellent results ${ }^{[5,6,7,8]}$.External fixation has a long history; it was first documented by Hippocrates when he used a splint for tibial fractures ${ }^{[9]}$. The development of external fixation devices that were directly attached to the bone started in the mid- $19^{\text {th }}$ century $[10,11,12,13,14]$. Langenbeck was the first to describe a technique that offered sufficient stability to the fracture site in $1851^{[15,16]}$. At the turn of the century, the concept of unilateral external fixation was invented ${ }^{[17,18,19]}$. In 1928, the swiss surgeon Raoul Hoffmann introduced an external fixation system concept that was able to provide length, alignment and rotational control in a rigid construct.

External fixation remains a versatile option for fixation of both open and closed fractures. However, pin-track infection and malunion are frequent complications ${ }^{[20]}$.Due to its wide range of indications, such as peri-articular fractures, articular dislocation and polytrauma ${ }^{[21,22,23,24,25,26]}$, external fixation stands out by its simplicity in regard to initial treatment ${ }^{[27]}$. Recently, an increasing rate of primary fracture treatment with spanning external fixation was observed and was explained by changes in logistics, economic aspects, or an increased use of damage-control techniques.

The purpose of this article is to report the clinical and radiological outcome of locked compression plating (LCP) and external fixation technique in management of proximal third tibia fracture.

\section{MATERIALS AND METHODS}

Adult patients suffering from proximal third tibial fractures that were treated with external fixator and locking compression plates between December 2014 and March 2015 were included in the study. The study was carried out on 40 patients with proximal third tibia fractures which were classified according to AO classification, type 41 A2 (transverse metaphyseal) and 41 A3 (comminuted metaphyseal) who received surgical treatment at the orthopedic units of the first affiliated hospital of Jiamusi university. Institutional Review Board approval and informed consent were obtained. Patients with articular extension were excluded. The subjects of the study were patients aging between $35 \sim 45$ years old, 22 male and 18 female .Patients were divided into 2 groups depending on the surgical 
treatment received ; observation group comprised of 20 patients treated by external fixation and the control group comprised of 20 patients treated by Open reduction internal fixation with locking compression plates. All patients were treated by experienced surgeons who were well familiar with the principles of external fixation and plating techniques .Pathological fractures, fractures due to malignancy were excluded from the study. Approximately six weeks after surgery, partial weight bearing was encouraged. Full weight bearing was not permitted until consolidation of the fracture site Clinical and radiological follow-up was performed at one-month, 2-months, 3-months, 6-months and 12-months post operatively for both groups Rehabilitation was started as the pain subsided with quadriceps exercises and continuous passive motion of the knee joints . Patients were systematically assessed for functional, clinical, radiological and subjective outcome into account like knee function, post operative infections, healing time, intra operative bleeding and intraoperative time, state of reduction after one week. Knee function was assessed and graded using Rasmussen Knee score. Clinical data was summarized and a data base established after which SPSS18.0 software was used to choose the appropriate statistical analysis method and conclusion were obtained.

\section{RESUlts}

There were no significant differences in the age, gender, sex and fracture distribution were found in both groups treated. Majority of the patients $85 \%(34 / 40)$ presented with isolated injuries. Mechanism of injury included athletic injuries 30\%(12/40), motor-vehicle accidents 40\%(16/40), domestic injuries 18\%(7/40) and other causes 12\%(5/40). In both groups no body suffered from deep wound infections. There were 3 cases of superficial pin tract infections, 1 case of superficial wound infection in the external fixation group, 2 cases of superficial wound infections in the LCP group which were managed with local pin site care and administration of antibiotics. Deep venous thrombosis and compartmental syndromes were not found in both the groups.

Table1. Comparing Post-operative complications in both groups

\begin{tabular}{llllcll}
\hline & & & & & \\
Groups & Pin tract & superficial & Deep & compartment & Bed & Delayed \\
& Infection & wounds & wound & syndrome & sores & union \\
\hline Ext.Fix & 3 & 1 & 0 & 0 & 0 & 1 \\
LCP & 0 & 2 & 0 & 0 & 1 & 0 \\
\hline
\end{tabular}

We compared the post operative complications in both groups of patients came to conclude that the ex.fix group has few post operative complications as compared to LCP group.

In this table we made two groups of patients and separated them on the basis of gender using chi square test ${ }^{\mathrm{X} 2}=0.902, \mathrm{P}=0.342>0.05$, which means there is no significant difference in the distribution of patients in both groups thus making these two groups comparable to each other in context of this study.

Table2. Comparing gender distribution in both groups

\begin{tabular}{lccccc}
\hline Groups & Male & Female & Total & X2 & P value \\
& & & & & \\
\hline Ext.Fix & 10 & 10 & 20 & 0.902 & 0.342 \\
LCP & 12 & 08 & 20 & & \\
\hline
\end{tabular}

The mean operation time was 90 minutes (80-105 min) for LCP and mean operation time for ext.fix was 50 minutes (40-65min). Mean blood loss was $160 \mathrm{~mL}(100-230 \mathrm{~mL})$ for LCP and mean blood loss was $25 \mathrm{ml}$ (20-40) for ext.fix group. Inscion length in LCP group is $10 \mathrm{~cm}$ and that in Ex. Fix group is about $3 \mathrm{~cm}$. 
Ismail Jan et al.

Table3. Comparing Intra-operative parameters of both groups

\begin{tabular}{lccc}
\hline Groups & Bleeding & operative time & Inscision length \\
& $(\mathrm{ml})$ & $(\mathrm{min})$ & $(\mathrm{cm})$ \\
\hline Ext.Fix & $20 \pm 05$ & $40 \pm 08$ & $3 \pm 0.5$ \\
LCP & $160 \pm 10$ & $90 \pm 10$ & $10 \pm 2$ \\
\hline
\end{tabular}

From this table we analyzed the results. We come to know that operation time, amount of bleeding and incision length are all comparatively of small magnitude in external fixation group as compared to the LCP group. These results are statistically significant.

Table4. Comparing mechanism of injury in both groups

\begin{tabular}{lllcll}
\hline Groups & Traffic & fall from & domestic & $\times 2$ & P value \\
& accidents & heights & falls & & \\
\hline Ext.Fix & 14 & 4 & 2 & 0.770 & 0.680 \\
LCP & 13 & 6 & 1 & & \\
\hline
\end{tabular}

Here two groups of patients were grouped and analyzed according to the cause of injury using chi square test. Majority of injuries occurred due to road traffic accidents followed by fall from heights and domestic falls .using chi square test we came to know that there are some small difference in the cause of injury but these differences are not statistically different and thus both groups are comparable to each other in this context. $\mathrm{X} 2=0.770, \mathrm{P}=0.680>0.05$.

Table5. Comparing both groups patients for side of injury

\begin{tabular}{lccccc}
\hline Groups & Right & Left & Total & x2 & P value \\
& & & & & \\
\hline Ext.fix & 12 & 08 & 20 & 0.519 & 0.417 \\
LCP & 11 & 09 & 20 & &
\end{tabular}

Two groups of patients were analyzed based on the side of the injury using chi-square test. $X^{2}=0.519$, $\mathrm{P}=0.417>0.05$ which means no statistically significant difference in both groups and thus these two groups are comparable to each other.

Table6. comparing both groups for types of fractures

\begin{tabular}{lccccc}
\hline Groups & AO 41A2 & AO 41A3 & TOTAL & $X^{2}$ & P value \\
& & & & & \\
\hline Ext ffix & 14 & 06 & 20 & 0.125 & 0.723 \\
LCP & 15 & 05 & 20 & &
\end{tabular}


Two groups of patients separated by fracture type were analyzed using rank sum test. $\mathrm{X}^{2}=0.125, \mathrm{P}=$ $0.723>0.05$ which means there was no statistically significant difference among the two groups which made them able to be compared against each other.

Table7. Comparing bone union time in both groups

\begin{tabular}{lccc}
\hline Groups & $\begin{array}{c}\text { healing time } \\
\text { (weeks) }\end{array}$ & $\begin{array}{l}\text { Range } \\
\text { (weeks) }\end{array}$ & $\begin{array}{c}\text { Ambulation } \\
\text { (weeks) }\end{array}$ \\
\hline Ext.fix & 14 & $10-24$ & $2 \pm 0.9$ \\
LCP & 16 & $10-28$ & $2 \pm 0.2$
\end{tabular}

Comparing both groups of patients on the basis of hospitalization time and time to bone union we come to know that in external fixation group the time for bone healing is comparatively shorter to that of LCP group. On the other hand the hospitalization is longer in orif group as compared to ext.fix group. These differences are statistically not significant and both groups can be compared.

\section{DisCUSSION}

\subsection{Key Findings}

Though LCP and external fixations both has good clinical results still the following points need discussion before planning surgery for patients undergoing proximal t $1 / 3$ tibia fracture. Importance of intra operative time is such that each extra hour of intra operative time increases infection chance by $78 \%$.From our results it is clear that intra operative time is much with LCP as compared to external fixation ${ }^{[28,29]}$. As the intraoperative time is more, there are more chances of developing deep venous thrombosis, pressure sore and pneumonia in patients with LCP technique there is excessive dissection of soft tissue and wide exposure of bone is necessary for good visuality of the fracture zone. Thus more dissection of soft tissue will have more chances of infections in such technique. On the other hand in external fixation method, there is no much dissection of soft tissue minimizing infection chances ${ }^{[30,31,32,33]}$.In LCP as we mentioned earlier, bone exposure is important and in this process we may destroy periosteum. Periosteum is important in blood supply to the fractured area. Damage to periosteum may alter bone healing process. In external fixation there is minimal or no damage to the underlying periosteum ${ }^{[34,35]}$.

It is obvious that with LCP technique, primary bone healing with absolute stability occurs which is slower than relative stability provided by external fixation. Thus comparatively it will take longer time in healing for LCP than that of external fixation ${ }^{[36,37,38]}$. We use general anesthesia for LCP technique and there are complications with it. On the other hand for external fixation regional anesthesia with less complication would be sufficient. In LCP technique, after the fracture is properly healed, implant removal will need a second time surgery. Again there would be dissection of soft tissue and infection chance maybe there. In external fixation there is no need of any second time surgery instead these fixator can be removed easily ${ }^{[39,40]}$.

Skin and soft tissues are allergic to implants. There may be pain and irritation due to implants like LCP and others. The implant has to be there in the fractured bone for a longer period of time as compared to external fixator. According to published data there is possibility of fatigue crack and implant failure in LCP technique ${ }^{[41,42,43]}$. Finally if we compare the costs of both the procedures, we come to know that LCP technique requires minimum two surgical procedures as compared to external fixators. Keeping this in mind and cost of LCP, external fixators are comparatively inexpensive. 


\section{Conclusions}

From this comparative study it is concluded that:

Both External Fixation and LCP are equally useful techniques External Fixation technique results in less amount of bleeding, less soft tissue dissection decreasing chances of infection and less periosteal damage decreasing union time compared to LCP technique.

External fixation results in less scar tissue formation and having short operative time decreasing the chances of post operative complication chances as compared to LCP technique. Furthermore with External Fixation technique, there is no need of surgical removal of implant as well, no need for general anesthesia which makes it cost effective compared to LCP technique.

\subsection{Conflict of Interest}

There are no conflicts of interest.

\section{REFERENCES}

[1] Court Brown CM, Christie J, McQueen M. Closed intramedullary tibial nailing. J Bone Joint Surg Br 1990;72:605-11

[2] Finkemeier CG, Schmidt AH, Kyle RF, Templeman DC, Varecka TT. A prospective, randomized study of intramedullary nails inserted with and without reamin for the treatment of open and closed fractures of the tibial shaft. J Orthop Trauma 2000;14:187-93

[3] Puno RM, Teynor JT, Nagano J, Gustilo RB. Critical analysis of results of treatment of 201 tibia shaft fractures. Clin Orthop Relat Res 1986;212:113-21.

[4] Tytherleigh Strong GM, Keating JF, Court Brown CM. Extraarticular fractures of the proximal tibial diaphysis: their epidemiology, management and outcome. J Roy Coll Surg Edin 1997;42:334-8

[5] Lindvall E, Sanders R, Dipasquale T, Herscovici D, Haidukewych G, Sagi C. Intramedullary nailing versus percutaneous locked plating of extraarticular proximal tibia fractures: comparison of 56 cases. J Orthop Trauma 2009;23(7): 485-92

[6] Cole PA, Zlowodzki M, Kregor PJ. Treatment of proximal tibia fractures using the less invasive stabilization system: surgical experience and early clinical results in 77 fractures. J Orthop Trauma 2004;18:528-35.

[7] Stannard JP, Wilson TC, Volgas DA, Alonso JE. Fracture stabilization of proximal tibial fractures with the proximal tibial LISS: early experience in Birmingham, Alabama (USA). Injury 2003;34(Suppl. 1):A36-42.

[8] Oh KJ, Oh CW, Kim SJ, Kyung HS, Park IH, Kim PT, Ihn JC. Percutaneous plate stabilization of proximal tibial fractures. J Trauma 2005;59:429-35

[9] Hippoc rates. The genuine works of Hippocrates. Baltimore: Williams and Wilkins; 1939

[10] Malgaig ne JF. Traité des fractures et des luxations. In. Paris: J.B. Balliére; 1847

[11] Malgaigne JF. Etudes statistiques sur les résultats des opérations dans les hôpitaux des Paris. In. Paris: Felix Locquin; 1858

[12] Cooper S. Tre atment of the fractured patella by Malgaigne's hooks. In: SanFran Med Press. 1861

[13] Klasen HJ. De schroef van Malgaigne, een vroeg hulpmiddel bij de repositie van fracturen. Ned J Trauma 1994;2:44.

[14] Gurlt EJ. Han dbuch der Lehre von den Knochenbrüchen. In. Hamm: G. Grote; 1862

[15] Labitzke R. Vo n der "Knochennaht" zu zeitgenössischen Osteosynthesen - eine Chronologie vol. 66;1995. 
[16] Freeman L. The treatment of oblique fractures of the tibia and other bones by means of external clamps inserted thorugh small openings in the skin. Trans Am Surg Assoc 1911; 28

[17] Labitzke R. Vo n der "Knochennaht" zu zeitgenössischen Osteosynthesen - eine Chronologie vol. 66;1995

[18] Parkhill C. A n ew apparatus for the fixation fo bones after resection an in fractures with a tendency to displacement. Trans Am Surg Assoc 1897;15.

[19] Parkhill C. Fu rther observations regarding the use of bone-clamp in ununited fractures, fractures with mal-union and recent fractures with a tendency to displacement. Ann Surg 1898;27

[20] Hutson JJ Jr, Zych GA: Infections in periarticular fractures of the lower extremity treated with tensioned wire hybrid fixators. J Orthop Trauma 1998; 12:214-218.

[21] Calori GM, Tag liabue L, Mazza E, de Bellis U, Pierannunzii L, Marelli BM, et al. Tibial pilon fractures: which method of treatment? Injury 2010;41(11):1183-90.

[22] Chhabra A, Cha PS, Rihn JA, Cole B, Bennett CH, Waltrip RL, Harner CD. Surgical management of knee dislocations. Surgical technique. J Bone Joint Surg Am 2005;87(Suppl 1 Pt 1):1-21.

[23] Pape HC, Torne tta P, 3rd, Tarkin I, Tzioupis C, Sabeson V, Olson SA. Timing of fracture fixation in multitrauma patients: the role of early total care and damage control surgery. J Am Acad Orthop Surg 2009;17(9):541-9.

[24] Lavini F, Dall 'Oca C, Mezzari S, Maluta T, Luminari E, Perusi F, Vecchini E, Magnan B. Temporary bridging external fixation in distal tibial fracture. Injury 2014;45 (Suppl 6):S58-63.

[25] Scaglione M, F abbri L, Dell' Omo D, Goffi A, Guido G. The role of external fixation in the treatment of humeral shaft fractures: a retrospective case study review on 85 humeral fractures. Injury 2015;46(2):265-9

[26] Corina G, Mori C, Vicenti G, Galante VN, Conserva V, Speciale D, et al. Heel displaced intra-articular fractures treated with mini-calcaneal external fixator. Injury 2014;45 (Suppl 6):S64-71

[27] Rixen D, Grass G, Sauerland S, Lefering R, Raum MR, Yucel N, et al. Evaluation of criteria for temporary external fixation in risk-adapted damage control orthopedic surgery of femurshaft fractures in multiple trauma patients: "evidence- based medicine" versus "reality" in the trauma registry of the German Trauma Society. J Trauma 2005;59(6):1375-94; discussion 1394-5

[28] Ball CG, Pitt HA, Kilbane ME, Dixon E, Sutherland FR, Lillemoe KD. Peri-operative blood transfusion and operative time are quality indicators for pancreatoduodenectomy.HPB (Oxford) 2010;12(September (7)):465-71

[29] Peersman G, Laskin R, Davis J, Peterson M. Infection in total knee replacement: a retrospective review of 6489 total knee replacements. Clinical Orthopaedics and Related Research 2001;392:15-23.

[30] Giannoudis PV, Einhorn TA, Marsh D. Fracture healing: the diamond concept.Injury 2007;38(4):S3-6.

[31] Demiralp B, Atesalp AS, Bozkurt M, et al. Spiral and oblique fractures of distal onethird of tibia-fibula: treatment results with circular external fixator. Ann Acad Med Singapore 2007;36(4):267-71

[32] Henley MB, Chapman JR, Agel J, Harvey EJ, Whorton AM, Swiontkowski MF.Treatment of type II, IIIA, and IIIB open fractures of the tibial shaft: a prospective comparison of unreamed interlocking intramedullary nails and half-pin externa fixators. J Orthop Trauma 1998;12(1):1-7. 
[33] Olson A. Instructional course lectures, The American Academy of Orthopaedic Surgeons - open fractures of the tibial shaft. Current treatment. J Bone Joint Surg[Am] 1996;78(9):1428-37.

[34] Murphy CP, D’Ambrosia R, Dabezies EJ: The small pin circular fixator for proximal tibial fractures with soft tissue compromise. Orthopedics 1991,14:273-280

[35] Giannoudis PV: Surgical priorities in damage control in polytrauma. JBone Joint Surg Br 2003, 85:478-483

[36] van Frank Haasnoot E, Münch TW, Matter P, et al (1995) Radiological sequences of healing in internal plates and splints of different contact surface to bone. (DCP, LCDCP and PC-Fix).Injury; 26 (Suppl 2):28-36

[37] Schenk R, Willenegger H (1963) [On the histological picture of socalled primary healing of pressure osteosynthesis in experimental osteotomies in the dog.] Experientia; 19:593-595.

[38] Rahn BA, Gallinaro P, Baltensperger A, et al (1971) Primary bone healing. An experimental study in the rabbit. J Bone Joint Surg Am; 53(4):783-786

[39] Langkamer VG, Ackroyd CE: Removal of forearm plates. A review of the complications. J Bone Joint Surg Br 1990, 72:601-604.

[40] Sanderson PL, Ryan W, Turner PG: Complications of metalwork removal. Injury 1992, 23:29-30.

[41] Beaupre GS, Csongradi JJ: Refracture risk after plate removal in the forearm. J Orthop Trauma 1996, 10:87-92.

[42] Davison BL: Refracture following plate removal in supracondylar-intercondylar femur fractures. Orthopedics 2003, 26:157-159.

[43] Miller D, Goswami T. A review of locking compression plate biomechanics and their advantages as internal fixators in fracture healing. Clin Biochem 2007;22(10):1049-62 